\title{
Editorial
}

\section{Congreso Chileno de Obstetricia y Ginecología}

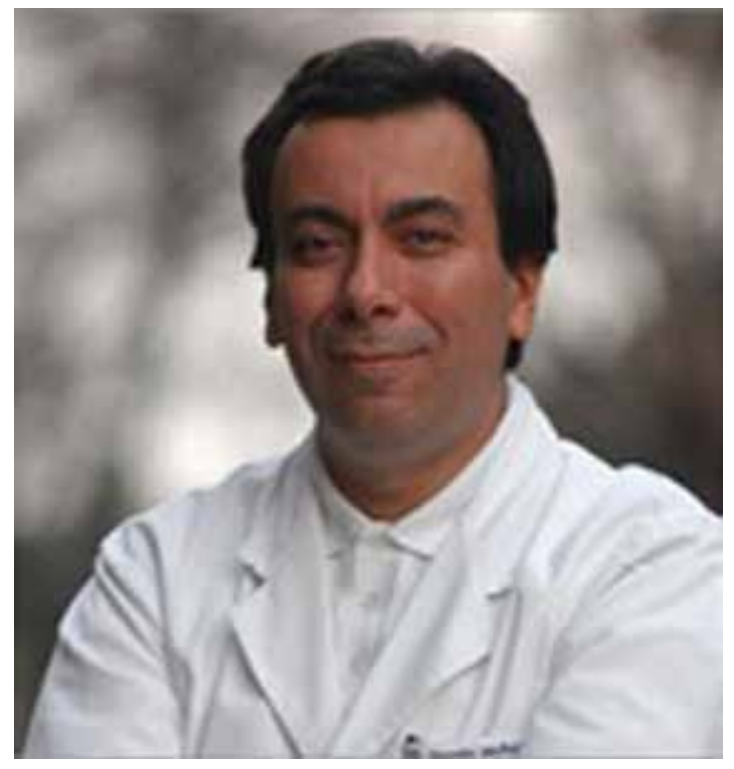

Es un honor y privilegio invitarlos al XXXIV Congreso Chileno de Obstetricia y Ginecología que se realizará en Viña del Mar, entre el 30 de noviembre y el 3 de diciembre de 2013, y que este año por primera vez lo estamos realizando en forma conjunta con la Sociedad Chilena de Climaterio, Sociedad Chilena de Medicina Reproductiva, Sociedad Chilena de Ginecología Oncológica y Sociedad Iberoamericana de Diagnóstico y Terapia Prenatal.

Porque entendemos el valor del trabajo en equipo, esta organización conjunta es el reflejo del espíritu colaborativo de nuestra sociedad científica. SOCHOG - en su rol de sociedad madre de la especialidad - asume y entiende la importancia de incorporar en sus actividades y medios de comunicación a todas las sociedades científicas derivadas de la ginecología y obstetricia. Así como a la Sociedad Iberoamericana de Diagnóstico y Terapia Prenatal.
El éxito de este trabajo mancomunado ha permitido, entre otros aspectos, contar con un programa científico de primer nivel donde se abordarán todas las áreas de nuestra especialidad, y donde contaremos con los máximos exponentes mundiales de cada una de ellas. Los invitados son todos líderes de opinión en sus respectivas áreas, y nos contarán los avances más recientes de la obstetricia y ginecología mundial. En total serán 12 invitados internacionales que participarán de este congreso.

Asimismo, tendremos el honor de tener la presencia del Dr. Sabaratnam Arulkumaran, Presidente de la Federación Internacional de Ginecología y Obstetricia (FIGO), y la Dra. Jeanne Conry, Presidenta del Colegio Americano de Obstetricia y Ginecología (ACOG).

En nuestras actividades incluiremos conferencias plenarias, sesiones temáticas de las especialidades, talleres y simposios. En esta oportunidad realizaremos, además, Reuniones de Consenso Latinoamericanas en ultrasonido de piso pélvico y en diagnóstico prenatal no invasivo.

Desde un punto de vista logístico - y dado que cada año hemos ido superando la cantidad de asistentes en nuestros congresos - en esta ocasión y en forma inédita realizaremos un evento de este tipo de manera simultánea en dos hoteles.

Tenemos contemplado que asistan alrededor de 1000 profesionales de la especialidad. Por lo tanto, este evento será además un excelente punto de encuentro con los colegas de Chile y de Latinoamérica. Para lo cual hemos preparado, además, diferentes actividades sociales.

Los invitamos a organizar sus agendas y a programarse para este gran congreso. Esperamos contar con todos ustedes.

Un fraternal abrazo. Dr. Hernán Muñoz S. Presidente. Sociedad Chilena de Obstetricia y Ginecología. 